\title{
Systems and algorithms of work for protecting electric traction networks
}

\author{
B.V. Malozyomov \\ Novosibirsk State Technical University \\ Novosibirsk, Russian Federation \\ mbv5@mail.ru
}

\begin{abstract}
The paper reviews the electric traction network analysis, the distinctive features of its functioning, innovative switching to digital protection, the first results of trial operation, proposals for further improvements, using the monitoring and level increase of the automation operating system of the traction feeder network.
\end{abstract}

Keywords - traction network, protection systems, voltage, electricity, current, control, algorithms

\section{INTRODUCTION}

Along with the economy growth and the metropolitan developments, utilization of the railway system has become one of the key parts of today's large cities traffic plan. As the railway system is one of the most important solutions for traffic issue in large cities, the occurrence of fault current may lead to delay in the routine operation of trains which in turn may affect the traffic management of the city. Additionally, fault currents may results in damaging the electrical equipment and safety devices. Therefore, research on the railway electrical system performance during fault condition has significant importance from the system security and reliability points of view.

In the Direct Current (DC) traction systems, due to a relatively low voltage level of the supply line and its high impedance, the amplitude of short-circuit current can be in the order of maximum start-up current drawn from substations. In this condition, fast and appropriate distinguishing between fault current and start-up current is a challenging issue by over-current relays. This condition is worse for short-circuit current occurred far from substations [1-2]. In [3], the modeling and the simulation of the electrical railway system have been fully described. Moreover, in [3] and [4], the new protection method known as line fault detection (LFD) has been introduced. In [5], besides introducing different structures of railway supply, the algorithm of the LFD method is evaluated.

Nowadays, the LFD protection method is used widely in the railway system, but its proper operation is extremely dependent on the dynamic impedance of the railway electrical system, as well as the effect of any changes made in the electrical railway system such as supply line, train motors, etc. These effects have been already investigated in some literatures [8-9]. In this paper, a new protection method entitled as an "Over-Load" scheme is proposed. The electrical system of the Siberian railway is simulated, and protection performance of LFD and proposed methods is compared by using the data obtained from other railways.

Different voltage levels, including $600 \mathrm{~V}, 650 \mathrm{~V}, 750 \mathrm{~V}$, $1500 \mathrm{~V}$ and $3000 \mathrm{~V}$, are used as power supply for DC traction systems. In the railway system, a $1500 \mathrm{~V}$ system is generated from a $20 \mathrm{kV}$ power network and is delivered to the train wagons through the Pantograph. The power network voltage level of $20 \mathrm{kV}$ is converted to a lower level, one through the two three-winding transformers in each substation and with the aid of rectifiers. Thus, the appropriate line voltage is generated and finally connected to the supply line. The substation which includes both transformers and rectifiers is referred to as a traction substation. It is worth to note that not all the substations are of this kind, and generally the number of such traction substations is related to the several parameters such as the number of passengers, total power demand, headway and also the number of trains. The output terminals of the rectifiers are connected to the bus-bars and then to the supply line through direct current circuit breakers. These connections are called "Feeders". There are two supply lines in this system, in which one line is intended for forward traveling trains supply and the next one is meant for returning trains.

Each traction substation is connected to each line through two circuit breakers and a bypass switch. The DC voltage is delivered to the train through Pantographs. The required threephase voltage for asynchronous motors of trains is provided by voltage source inverters, located inside the trains. The motors are controlled using variable voltage and the frequency $(V / F=$ Const. $)$ method. Moreover, a portion of the train input power is allocated to the internal power consumption in which the required voltage level is generated according to the application.

Due to some special circumstances like malfunction in the operation of the substation, it is possible to supply the trains by one or two substations. Based on the type of energizing the trains, there are different supply schemes including normal, one-sided, bypass and T-form [5]. In a normal scheme, all of the circuit breakers are closed and the isolators of substations are opened. Usually two trains can be located between two traction substations, and their required supply current is provided by both substations. There may also be one or more non-traction substations, known as an auxiliary substation between the aforementioned traction substations.

The electric transport is a keynote kind of a vehicle of the country's inbound logistics, having a great impact on the 
infrastructure development of cities and the country at large. There is a cargo turnover on Russian Carriers, passenger traffic flows in million-cities, long hauls between cities (e.g. Crimea trolley-bus from Simferopol to Yalta), or a city and a big manufacturing area (e.g. in Chelyabinsk and St. Petersburg), given that the train's proper weight is becoming larger as well as the speed and the power rating of locomotive engines and electric trains increase. Besides, the schedule speed and comfort increased (e.g. electric train "Sapsan"); new subway and tramcars were developed. These innovations upgrade the quality of reliability of the electric transport power-supply system.

The peculiarities of the electric transport power-supply system are as follows:

1. sudden fluctuating loads in magnitude and place of application in the traction network, load currents are comparable with short currents (SC);

2. load currents in many cases are practically close to SC in the remote access point;

3. when crossing an electric train from feeder to feeder, the current collector can break off etc., critical current steps $(\Delta I)$ can occur with steep front $(d i / d t)$;

4. irregularity of a traction network along the length, active and full resistance (stations, integrations, moving electric trains etc.);

5. tracks and the bound ground, in parallel with changing conductivity in relation to the environment, are run into the return circuit (a nonlinear ferromagnetic element of electrical circuitry with variable parameters);

6. the traction network has the network of circuit sectioning, powered by some sources of the adjacent track outlet, and it results in the necessity of de-energizing the fault location with several cutoff switches simultaneously;

7. low thermal electric conductors of the contact system and the electric train facilities, requiring the point of fault deenergizing with minimum time;

8. a great number of short currents in electric trains are often left unknown (reasons and locations) and it makes it difficult to analyze the performance protection

The statistics of protection of operating characteristics of a traction network from abnormal modes in many cases is characterized by low reliability and it does not comply with the requirements of electrical installation code (EIC). At Russian Railways and city electric transport (subway, tram and trolley-bus), the maximum impulse protection (MIP) is used as a generic one, where one system of d.c. relay, for instance, a kind of DCR, carries out two types of current protection: the maximum current protection (MCP) and the gain current protection (GCP). Sometimes special protection types are used (current time dependence, thermal, frequencyresponse lines, with current frequency and voltage analysis, with traction network insulation testing $(\mathrm{TN})$, automatic blocking).

\section{THEORY}

The data of maximum current protection functioning (MCP) were obtained on the testing field of the West-Siberian Carrier (18 traction substations TSS, 70 protection equipment of railway feeder RF): in 2011, there were 4240 operations; in 2012, there were 4434 operations; the total amount of operations on the testing field were 8554. The numerical characteristic of operations [1] is the following:

The average value is:

$$
M(x)=\sum_{i=1}^{n} x_{i} \cdot p_{i},
$$

where $x_{i}$ is a chance variable; $p_{i}$ is a probability of the chance variable.

Root mean square (RMS) is:

$$
\sigma(x)=\sqrt{\sum_{i=1}^{n}\left(x_{i}-m_{x}\right)^{2} \cdot p_{i}}
$$

Dispersity is:

$$
D(x)=\sum_{i=1}^{n}\left(x_{i}-m_{x}\right)^{2} \cdot p_{i}
$$

The outcome analysis of the experiment is given below.

As each cutting-off is an emergency, then in the section of power supply, 350 damages of contact network devices or electric trains took place on average (ET) in 2011. According to the failure-recording system (KASANT) of machinery the power supply system, 24 failures, constituting damage to machinery of the traction network (TN), traction substations (TSS), and 10 failures of electric trains took place during the year. The total amount of failures $N_{T A F}$ of traction energy machinery is:

$$
N_{T A F}=N_{F T S S}+N_{F C N},
$$

where $N_{F T S S}, N_{F C N}$ are the amount of failures of traction substations, the contact network being registered in the KASANT system. Then the total amount of protection operation is $N_{P O}$ :

$$
N_{P O}=K \cdot N_{T A F}+K E \cdot N_{F E T}+K \cdot N_{F N R}+N_{F R P}
$$

where $N_{F E T}$ is the amount of failures of electric trains on power supply sections; $N_{F N R}$ is the amount of failures which are not registered in the system; $N_{F R P}$ is the amount of false responses of the device protection; $K$ is a factor, noting repeated unsuccessful startups of instantaneous circuit breaker (ICB) taken equal to $3 ; K E$ is a number of repeated startups of instantaneous circuit breaker on short currents (SC) in electric trains (ET). Due to the minute analysis of electric train damages, $K E$ is taken equal to 5 in the experiment. Factor 
$K E$ is difficult to assess in terms of quantity, except for a single startup of an instantaneous circuit breaker from automatic repeated startups. A power dispatcher can start up an ICB during several times according to a telemetry control principle having nothing on SC availability. Using 5, one can define the amount of false responses of the machinery protection as:

$$
N_{F R P}=N_{P O}-K \cdot N_{T A F}+K E \cdot N_{F E T}+K \cdot N_{F N R},
$$

and numerically as:

$$
N_{F R P}=4240-3 \cdot 24+5 \cdot 10+3 \cdot 50=3968 \text {. }
$$

Consequently, there were 3968 of false responses of the machinery protection during 2011 on power supply sections (70 feeders of the traction network), and there were only 232 proper operations of the gross amount of 4240. Then the amount of false responses during a month on average is 330, but there are 19 short circuit (SC) responses.

\section{EXPERIMENT}

At present, in the national power industry, the device protection reliability is measured as a percentage of proper operations (so called a percentage of proper operations). The number, supplementing this indicator to 100 is a percentage of excessive and false responses (it is expressed as a percentage).

Therefore, in the experiment, a percentage of proper operations of the device protection was $10 \%$ and false responses $-90 \%$. It proves an inadequate operation of the existing protection.

The assessment technique of the functioning protection and the set-point selection could be useful for operating personnel for both digital protection and maximum impulse protection (MIP), which will be in operation activity for at least a decade. Let us take one example: on the West-Siberian Carrier with terminals like -In-Ter-3,3, 78 feeders of 755 were equipped, through the road net - 1416 feeders were equipped with approximately 5660 units respectively for 10 years.

The selection method of the protection types and set point computing for the current analog and digital protection are defined by the instruction of Plc "Russian Carriers" [2], due to which for every type of protection, the group of its position is used: main, back-up and additional protections. The main protection keeps the complete length of the intersubstation area and the time of its operation is less than other protections, overlapping the same area $[7,8]$.

The back-up protection (MCP) or CC (current cutoff) are designed for doubling the main protection given that the length of the protecting zone at the back-up protection should be no less than the main protection, but the time-delay towards operation can take place here. The complexity of providing reliable functioning is that the main and back-up protections are actualized with assistance of one electrical-mechanical relay of DCR type and this is MIP [3, 4]. But MCP or CC could be actualized virtually by means of the set-point selection. The above-mentioned special protections are used as additional ones.
Nowadays, some global majors produce controllers, emergency control facilities and feeder protection devices of the traction network (further "terminal") DC with voltage of $3.3 \mathrm{kV} 1.5 \mathrm{kV}, 825 \mathrm{~V}, 750 \mathrm{~V}$ and $600 \mathrm{~V}$ for overland and underground electric transport $[9,10]$.

Digital protections have a wider range of set-points and separate (in contrast to MCP) sensors of absolute current value - $I$ and its gain - $\Delta I$ (controller calculates) for the given setpoint time, $\Delta t$, the processing unit is continuously calculating the rate of current change $d i / d t$. In some devices, it is possible to analyze the heating of wires, the calculation of availability and distance to the fault location, the insulation testing of feeder cables ( version for city electric transport) and the capability of front porting of special protections (e.g. frequency-response block signaling, etc.). However, some problems related to the calculation and choice of digital protection terminal set-points can emerge $[5,6]$.

The Electrotechnical Unit Department of Novosibirsk State Technical University developed and tested the technique for MCP and innovations implementing digital protections on the testing field. The main guidelines of the technique are as follows:

1. the parameter evaluation of the traction network area;

2. the choice of calculation models for normal, imposed and emergency modes;

3 . the database creation, which is necessary for the load and s/c current calculation (short-circuit current);

4. making calculations using the «Kortes» software application or any other analytical approach;

5. the parameter control affecting the specific protection feeder functioning of the mathematical model using the packages of mathematic simulation Simulink as a part of MATLAB;

6. the choice of the view and action area of the main protection, ascertaining the capabilities of the back-up protections;

7. the set-point protection calculation, filling in the setpoint chart;

8. checking the functioning and security of the traction network by constructing a zone closure diagram, with at least three types of protection in each zone.

In electronic protections, a fundamentally new method for determining the value of current increments was implemented, which allows one to separately realize the functions of MIP, $\mathrm{CC}$ and $\mathrm{MCP}$, the latter is performed as bi-directional. As additional protections, the rate of current increase of $d i / d t$ (instantaneous magnitude in a scan time which is equal to 2 $m s$ ) and current gain $\Delta I$ in a time of $t$ (average value of $d i / d t$ ) can be used. Block signaling, thermal protection can 
be used as back-up protections with remote-control ( $U / R$ ) or

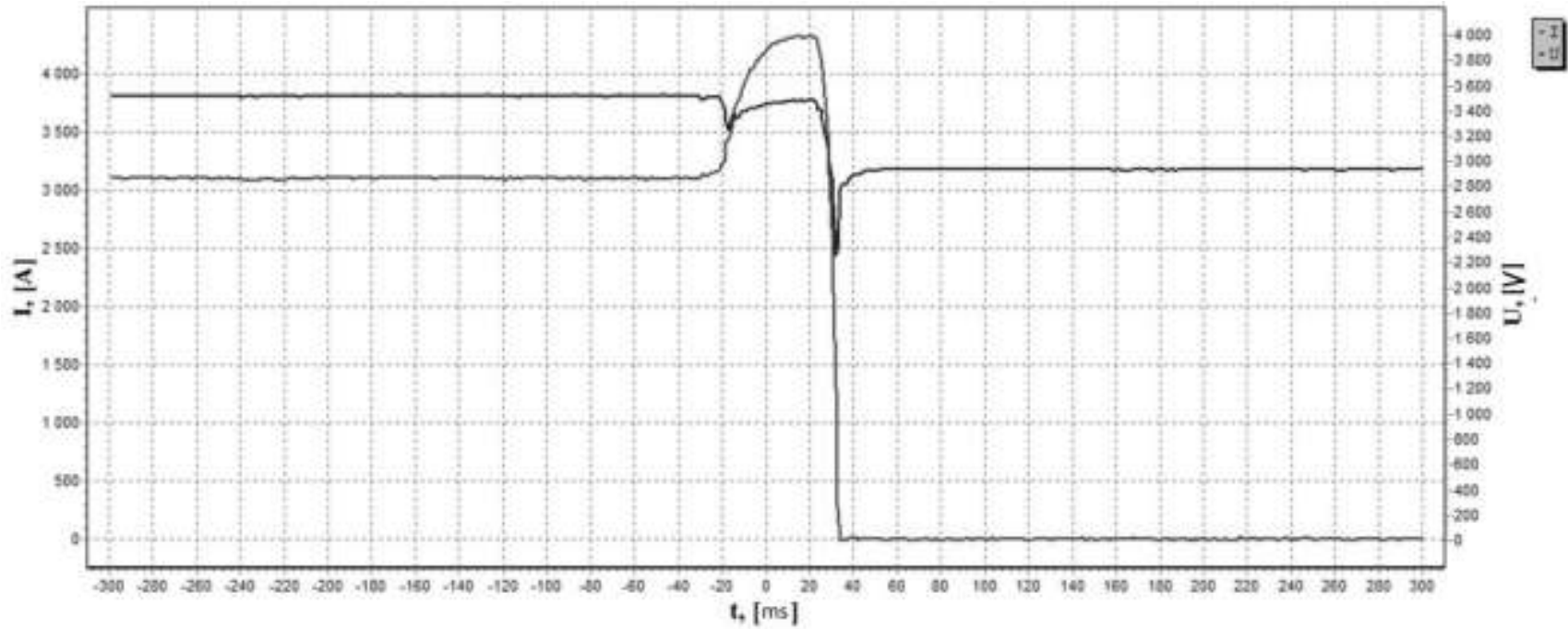

a)

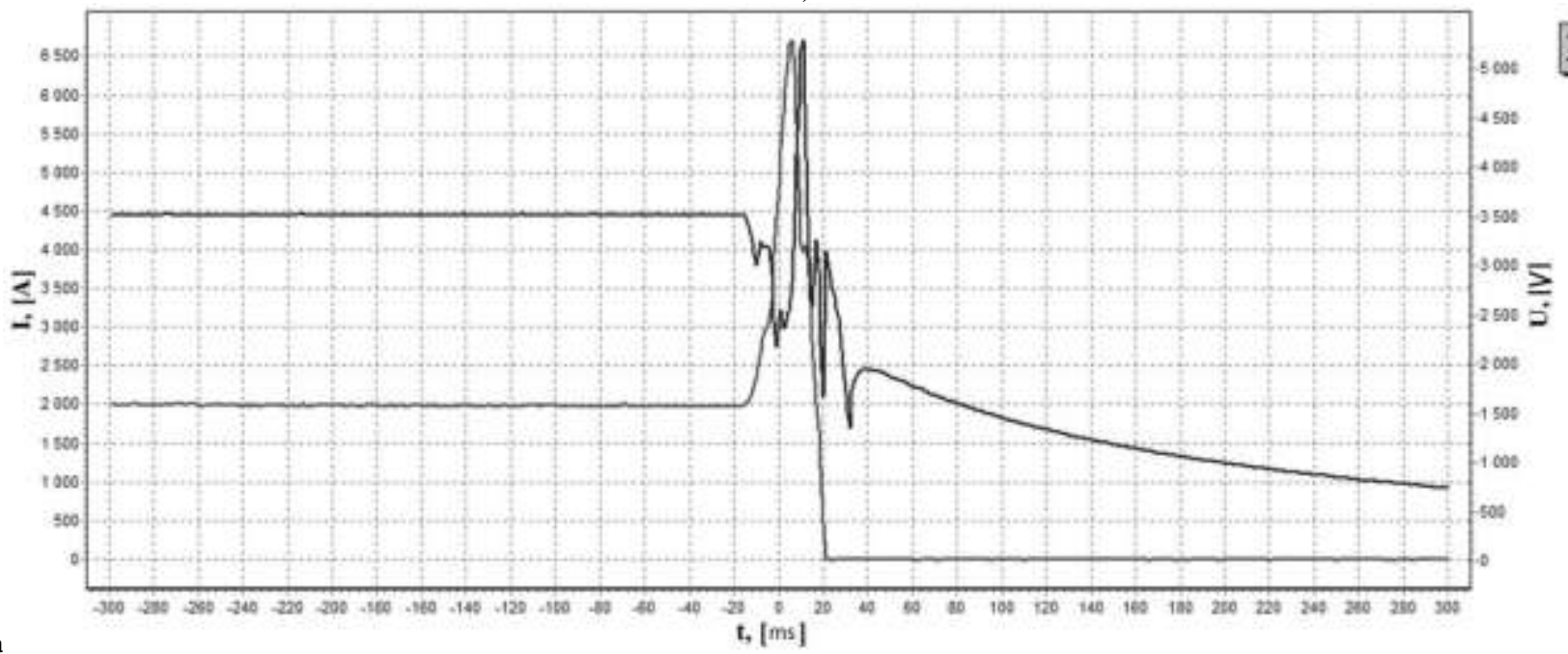

b)

Fig. 1. Oscillograms from terminal: a) in the mode of overload, b) in the mode of short circuit

current gain in a time of $t$. In this connection, the problem of set-point selection, using the rate of the current increase and amperage due to its dependence on the traction network performance, can emerge. Therefore, currently a lot of installed digital protections are used in the mode «on signal». The method of set-point selection is in [2].

The monitoring current system in traction network is offered for the secured terminal adjustment. The major purpose of the monitoring is:

- the definition of current and voltage change in the traffic mode of electric trains through the intersubstation area (standard operating procedure) and in case of error of TSS, TN and ET (operating emergency conditions);

the efficiency analysis of TN performance with parameters used when calculating set-points of separate terminal protections and making recommendations on the protection type selection [3] for each RF (railway feeder) setpoints. The next update serves to provide appropriate protection performance and secured de-energizing when errors occur. In this regard, it is necessary to control instantaneous current and voltage in real-time. In the system of monitoring, a computer is hooked up to the terminal providing permanent connection of PC with RF terminal [4].

Data transfer, monitoring and terminal interaction with IBM PC are carried out by using the software. This software enables one to read data from the terminal memory some additional information of current and voltage in the form of oscillograms in $300 \mathrm{~ms}$ before starting the transition process, under stationary (Figure 1a) and operating emergency conditions (Figure 1b). It also generates parameters, designating the mode (the rate of current gain change, the total value of current and voltage, a number of radiant quantities). 


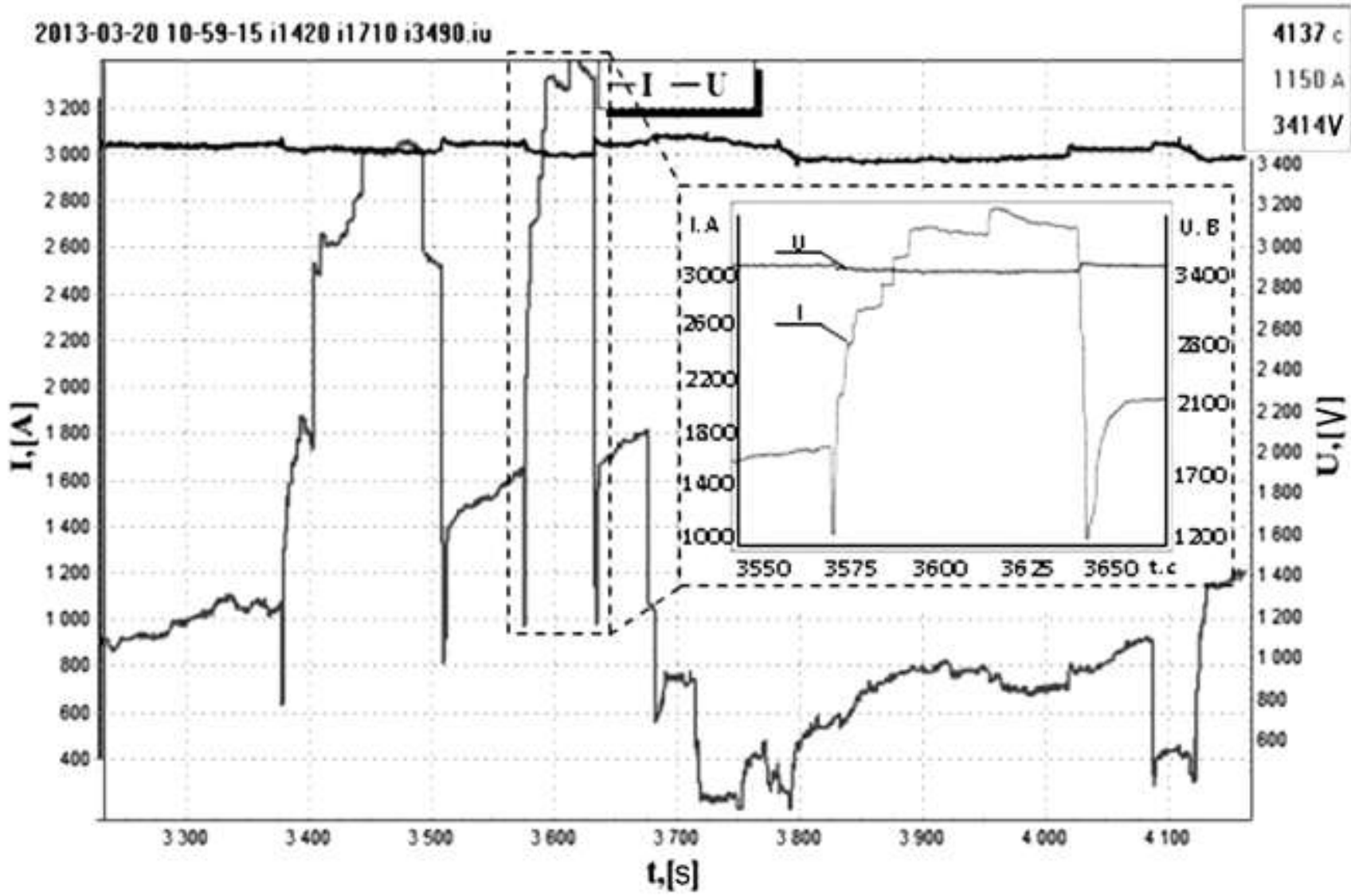

Fig. 2. Oscillograms stitching of two related feeders to analyse current and speed changes when crossing the power collector through the section of IC.

The storage system allows reading in 23 emergency cutoffs, which can take place within a month. This thing makes it difficult to have a systematic monitoring as required for updating set-points. Therefore, the system of remote access is arranged, enabling one to implement the information readout of all terminals from one center, for instance TSS or a zone of $\mathrm{TN}$, containing several substations and stores it in IBM PC. Using the monitor, one can watch, read in and retain continuous variation of feeder current for its further analysis and set-point updating, provided there were no emergency cutoffs (e.g. the over-tonnaged train handling through the section insulator crossing).

Figure 2 shows the fragment of TN parameters in the section insulator-crossing mode (IC).

\section{CONCLUSIONS}

The method of RF set-point protection designing was introduced using the mathematic simulation and monitoring. For continuous analysis of timely and effective set-point updating due to varied criteria, the remote access to the terminals was proposed.

\section{References}

[1] V.I.Sopov, V.V. Biryukov, Y.A. Prokushev, Y.A. Rylov, "Analysis of power supply systems for rolling stock with various schemes of traction networks", Abstract journal of VINITI RAS: Transport, Science, Engineering, Management, vol. 2 (2008), pp. 49-53, 2008.

[2] V. G. Sysenko VG, D.A. Bosvit, E.N. Kosarev, "Improvement of the methodology for calculating the distributed traction power-supply system with an amplifying point", Power electronics and power engineering, vol. 9, pp. 8-18, 2014.

[3] O.I. Sablin, "Improving the efficiency of energy recovery in the electric transport system with limited traction power supply", Technological audit and production reserves, vol. 5/1, pp. 21-26, 2014.

[4] V.V. Biryukov, A.V. Kulekina, "The calculation features of the electrical energy storage devices parameters in transport", IFOST 2016, pp. 41-43, June 2016 [The 11 International forum on strategic technology, p. 596, 2016]

[5] V.I. Sopov, N.I. Schurov, Y.A. Prokushev and A.A. Shtang, "Increasing the efficiency of the use of electrical energy in the sub-subsystem of electric transport", Improvement of technical means of electric transport, vol. 3 (29), pp. 115-123, Jule 2002 [Digest of scientific works of the NSTU, p. 189, 2002].

[6] E.N. Bykov, B.V.Panin, V.N.Pupynin, Traction networks of subways, Moskow: Transport, 1987.

[7] M.V. Tarnizhevsky, D.K. Tomlyakovich, Design of power supply devices for trams and trolleybuses, Moskow: Transport, 1986.

[8] K.G. Marquardt, Electrosupply of Electrified Railways, Moskow: Transport, 1982.

[9] M.A. Sleptsov, Fundamentals of Electric Transport, Moskow: Academy, 2006.

[10] L.A. Bessonov, Theoretical bases of electrical engineering, Moscow: Higher School, 1973. 